\title{
Bibliotecas virtuais: (r)evolução?
}

\section{Marília Levacov}

\section{Resumo}

As novas tecnologias da Informação estão criando "bibliotecas sem paredes para livros sem páginas". Mais conhecidas como bibliotecas virtuais, estas novas formas e suportes estão redefinindo os paradigmas atuais sobre informação, comunicação e o próprio âmbito de trabalho dos profissionais da área. Interdisciplinaridade e interatividade tornam-se as novas palavras de ordem. À medida que avançamos na chamada Era da Informação, esta transição faz surgir a necessidade de repensar os modelos éticos, legais, estéticos, culturais, profissionais e outros, estabelecidos pelo suporte impresso. Ocorrendo paralelamente off e on-line, a também chamada

Revolução da Informação utiliza ampla gama de aplicativos e equipamentos para tornar-se operativa. Coleção versus acesso, usuário local versus remoto, indexação hierárquica ou hipertextual, imprimir e distribuir ou distribuir e imprimir, navegar no oceano da informação ou afogar-se?

Este artigo pretende discutir essas questões dentro de um enfoque diacrônico e interdisciplinar, contribuindo para o debate e a reflexão que a convergência de mídias para o suporte digital faz surgir.

\section{INTRODUÇÃO}

\section{A passagem do impresso para o digital}

Vive-se atualmente uma transição tão importante quanto a que o mundo assistiu com aquela desencadeada pela convergência do uso de tipos móveis e de papel barato (comparado com o custo do pergaminho) no processo de produção de livros, jornais, mapas e, por conseguinte, de conhecimento, quando da passagem do texto manuscrito para o impresso. Diferentemente daquela, entretanto, esta está sendo fartamente documentada. Aliás, o excesso de informação é uma de suas características. Todas as atividades relacionadas com a manipulação, a edição, o armazenamento, a distribuição e recuperação da informação, assim como todas as formas de trabalho que lidem diretamente com dados textuais, simbólicos, numéricos, visuais e até mesmo auditivos, precisam agora adequar-se à forma digital.

A tecnologia é um catalisador de mudanças particularmente importantes e pungentes para as bibliotecas, uma vez que cria novas necessidades e altera velhos e sólidos paradigmas estabelecidos ao longo de muitos séculos. A decorrência maior desta transição é que a informação torna-se cada vez menos ligada ao objeto físico que a contém.

Bauwens ${ }^{1}$, em um documento eletrônico intitulado The Cybrarians Manifesto, analisando a mudança que as novas tecnologias trazem ao papel do bibliotecário, afirma que esta era uma profissão tradicionalmente ligada a um produto (o livro) e um local (a biblioteca). Seus clientes deveriam transportar-se fisicamente até tal local para acessar à informação desejada.

\section{Palavras-chave}

Isto se torna cada vez menos verdadeiro ou necessário atualmente. Graças às novas tecnologias da informação, está sendo modelado o que Browning ${ }^{2}$ chamou de "bibliotecas sem paredes para livros sem páginas". Neste e em outros campos, estas novas tecnologias estão gestando os sinais que começam a redefinir o que informação e comunicação virão a ser no Terceiro Milênio, bem como a cultura e os comportamentos que elas oportunizarão.

As mídias digitais estão substituindo o papel em uma variedade de aplicações e em uma velocidade vertiginosa. Ao mesmo tempo, criar, acessar, disponibilizar uma coleção virtual representa uma "coleção" de problemas. Este artigo pretende abordar alguns destes problemas, as razões pelas quais vale a pena enfrentá-los e algumas das conseqüências práticas e filosóficas que tal situação traz para os profissionais da informação. $O$ assunto Bibliotecas Virtuais é vasto e complexo. O presente artigo pretende apenas contribuir para o debate existente e servir de veículo às minhas reflexões sobre o assunto.

\section{(R)evolução da informação}

Da mesma forma como a Revolução Industrial não eliminou a agricultura, mas a marginalizou de forma crescente como fonte de renda, trabalho e poder, a Revolução da Informação faz migrar o capital para a própria informação, sua distribuição e recuperação. A sociedade e a economia tornam-se, cada vez mais, information-based. O declínio acentuado dos custos de hardware e software e o crescimento extraordinário do acesso comercial auxiliam e aceleram esta transição. "Ao subverter a economia de produção em massa, as novas tecnologias da informação estão diminuindo os custos da diversidade, tanto em produtos quanto pessoal, desmassificando nossas instituições e nossa cultura, bem como criando um novo potencial para a 
liberdade humana, uma vez que eliminam a necessidade do paradigma institucional central da vida moderna: a burocratização"3.

\section{Diferentes conceitos de biblioteca virtual}

A idéia de bibliotecas virtuais tem feito aflorar diferentes conceitos e sentimentos ${ }^{4}$. Para alguns, significa simplesmente a troca de informações por meio da mídia eletrônica e pode abranger uma grande variedade de aplicativos, desde aqueles que utilizam simples caracteres ASCII, até aqueles que envolvam dados baseados em tempo (como vídeo, áudio, animações, simulações etc.).

Para outros, significa a possibilidade de concretizar o visionário sonho do Projeto $X a n a d{ }^{5}$, de Ted Nelson: criar uma rede mundial que fosse um grande depositário (potencialmente infinito) de todos os documentos da humanidade. Estes documentos, arquivados em uma estrutura universal de dados, poderiam apontar de modo associativo para outros documentos afins, tendo em comum sua natureza digital e hipertextual, no qual os links redefinem a fronteira entre um documento e outro.

Para outros ainda, desperta um grande medo a obsolecência do bibliotecário ${ }^{6}$, principalmente com o desenvolvimento de interfaces inteligentes que auxiliam os usuários na recuperação de informações on-line. Cada vez mais, entretanto, tal assunto é visto também como Lancaster $^{7}$ o percebe, isto é, dentro de uma definição dinâmica, como uma oportunidade para os profissionais da informação de combinar atividades altamente especializadas, exigidas pela realidade tecnológica, bem como de expandir seu campo de trabalho e influência.

\section{Os novos conceitos de "lugar" e "tempo"}

Uma das primeiras coisas que mudam, quando se comparam as características de uma biblioteca concreta com uma virtual é que, graças às tecnologias das telecomunicações em rede, onde o documento reside não é mais importante. O conceito de "lugar" torna-se secundário, tanto para bibliotecários quanto para usuários. O que é importante passa a ser o "acesso" e, com freqüência, a "confiabilidade" da informação. Em outras palavras, é importante saber quem a produziu, quem a identificou como valiosa, quem a selecionou para uso comum, quem a disponibiliza e quem garante sua autenticidade. A biblioteca virtual, com freqüência, aponta para as fontes de informação sem, necessariamente, possuir a propriedade física das mesmas. "O conhecimento humano está atualmente disperso no espaço, desdobrando-se em um tempo descontínuo"8.

O conceito de "tempo" também se altera. Virilio ${ }^{9}$, por exemplo, observa que se nota alguma perda de orientação espacial e temporal, pois o conceito local de tempo torna-se secundário. Isto não significa que exista uma globalização, mas sim uma virtualização ou uma "relativização" do tempo: a instantaneidade passa a ser a palavra de ordem. Levy ${ }^{10}$ chama isto de "velocidades qualitativas e espaço-tempo mutantes". Soluções como o Comut não mais atendem às necessidades de acesso imediato aos documentos que a informação em rede oportuniza.

Outra vantagem deste novo conceito de tempo é apontada por Harnad ${ }^{11}$, que sugere aos autores acadêmicos 0 aproveitamento das facilidades da Internet para se autopublicarem. Desta forma, evitariam o longo tempo entre a submissão de um artigo e sua publicação, o que cria margem (em determinadas áreas) a que as conclusões se obsoletizem ou que outros indivíduos publiquem os mesmos resultados antes, em outras fontes mais dinâmicas.

Também a velocidade das mudanças tecnológicas, que pode ser medida em meses às vezes, comparada a processos equivalentes nas mídias anteriores (que demoravam séculos), cria confusão e stress entre bibliotecários e usuários. Não há sequer consenso em prever quais serão as necessidades de uma biblioteca daqui a uma década, o que dificulta enormemente os planejamentos na área.

\section{A construção das bibliotecas virtuais}

A construção das bibliotecas virtuais foi acontecendo aos poucos, à medida que a evolução da tecnologia disponibilizava novas ferramentas que podiam ser utilizadas para este fim. Esta construção ocorreu (e ainda ocorre) paralelamente em dois fronts: off e on-line ${ }^{12}$. A parte off-line iniciou com o controle do inventário e circulação, depois com a criação de catálogos eletrônicos e a automação de atividades de indexação. Mais tarde, acrescentou versões eletrônicas de obras de referência, geralmente em CD-ROMs (índices de periódicos e jornais, abstracts etc.). E, finalmente, o armazenamento e recuperação de versões eletrônicas da própria informação. De índices de periódicos, a sumários, abstracts e, por fim, full-text ${ }^{13}$ e acesso a bases de dados on-line e/ou na Internet.

Paralelamente, por duas décadas, a evolução das comunicações on-line foi criando recursos que os bibliotecários passaram a utilizar, como ftp (e archie), depois gophers (e veronica, WAIS etc.), OPACS (e Z39.50) e atualmente WWW (e indexadores como Yahoo ou robots indexadores como o AltaVista, Lykos, WebCrawler etc.), integrando-os gradualmente aos recursos off-line. Mais ain$\mathrm{da}$, as bibliotecas e os centros de informação começam a disponibilizar eletronicamente outras informações, de natureza mais comunitária, como calendários de eventos, informações locais etc. A biblioteca deixa de ser um tranqüilo depósito de livros para tornar-se o ponto focal de pesquisa variada, acessada a qualquer hora por usuários virtuais de vários lugares do mundo.

\section{Investir na coleção ou no acesso?}

A questão do acesso na biblioteca torna-se cada vez mais importante e é bidirecional. Localmente, possuir a propriedade física da informação em átomos, como diria Negroponte ${ }^{14}$, seja impressa ou em CD-ROM, ou pagar pelo acesso on-line, é uma decisão que precisa ser feita cada vez com mais freqüência. Não é uma decisão fácil, existem muitas variáveis envolvidas e implica que, "... no futuro, as bibliotecas terão um acervo menos tangível para justificar o dinheiro gasto"15, contrariando 
a filosofia que orientou as bibliotecas tradicionais até recentemente. $\mathrm{O}$ acesso local garante a "posse" da informação, o resultado concreto do investimento realizado. $\mathrm{O}$ acesso on-line, além de mais barato, possui um potencial impossível de ser igualado pela posse do documento impresso (ou em CD-ROM), mas seu produto é, freqüentemente, intangível.

Externamente, nota-se crescente preocupação dos profissionais da informação com o acesso global, e não apenas local. Isto é, com o acesso que o usuário remoto faz à coleção daquela biblioteca em particular, em oposição ao que o usuário local da biblioteca faz a coleções remotas. Por esta razão, disponibilizar o catálogo bibliográfico (pelo menos) e as bases de dados locais on-line (quando possível) permitem que aquela biblioteca em particular se torne um elemento a mais na grande gestalt informacional, justificando projetos e investimentos na área.

\section{O usuário remoto}

Com a possibilidade de acessar bibliotecas, centros de informação e bancos de dados via redes de telecomunicação, os usuários remotos já não serão mais um diminuto segmento do grande grupo de usuários. Ao contrário, cada vez mais reduzir-se-á o número daqueles que fazem o acesso real em comparação aos que fazem o acesso virtual. O próprio staff da biblioteca torna-se, por sua vez, usuário remoto de outras e necessita desenvolver novos métodos de instrução bibliográfica, reinventando sua profissão e os serviços que oferece ${ }^{16}$. O aumento crescente e maciço do número de usuários remotos exige também que a biblioteca mude seu foco. Como observa Wielhorski, "não são mais os usuários que se encontram distantes das bibliotecas, e sim as bibliotecas que se encontram distantes dos usuários"17. É importante que bibliotecários participem do desenvolvimento de metaferramentas que permitam a estes usuários (com diferentes habilidades computacionais) recuperar eficientemente as informações desejadas em um ambiente informacional cada vez mais complexo.

\section{TIPOS DE DOCUMENTOS DISPONÍVEIS}

\section{Catálogos}

Em 1969, Frederick Kilgmore criou um catálogo cooperativo e compartilhado organizando um consórcio de bibliotecas acadêmicas em Ohio, baseado no pressentimento de que brevemente as bibliotecas utilizariam os computadores para armazenar e ordenar seus catálogos e achando também que seria tolice reproduzir infinitas vezes os mesmos dados. Atualmente este consórcio, intitulado Ohio Colleges Library Center $(\mathrm{OCLC})^{18}$, permite que mais de $21 \mathrm{mil}$ bibliotecas, em 62 países, compartilhem um banco de dados de indexação com mais de 30 milhões de registros. A idéia de disponibilizar estes e quaisquer catálogos na Internet foi uma decorrência natural.

O sucesso do OCLC fez com que um número crescente de grupos semelhantes também oferecessem o compartilhamento de serviços de catalogação, produção de fichas bibliográficas, aquisição de periódicos etc. Entre eles, o Research Library Group, Washington Library Network, Amigos e muitos outros.

Hoje em dia, catálogos eletrônicos on-line, conhecidos na Internet como OPACs (On-line Public Access Catalogs) tornaram-se comuns e alguns apresentam interfaces bastante sofisticadas. "Prateleiras virtuais" reúnem coleções geograficamente dispersas e podem ser construídas instantaneamente por meio de diferentes campos indexadores. O conceito de operadores lógicos booleanos, antes restritos aos profissionais da informação, integram agora, em menos de uma década, o vocabulário dos usuários.

\section{Tipos de indexação (de hierárquicos a hipertextuais)}

Afastando-se dos bancos de dados hierárquicos convencionais, a informação dinâmica (em permanente mudança ou expansão), como é a do ciberespaço, exige a criação de documentos não estáticos, onde as âncoras para novas informações possam ser constantemente refeitas e a navegação entre recursos tão heterogêneos seja a mais "natural" possível.
Segundo Levy ${ }^{19}$, o hipertexto é visto como uma alternativa não apenas técnico-evolutiva de tratamento da informação, mas também como um reencontro com formas mais naturais (associativas) de produzir conhecimento. Segundo este, as tecnologias intelectuais quase sempre exteriorizam e retificam alguma função cognitiva, alguma atividade mental. Com a escrita, mais especificamente com a escrita alfabética (e a tecnologia da impressão), as formas narrativas das sociedades orais deram espaço aos modos teóricos de conhecimento, criando uma ecologia cognitiva estruturada no documento escrito, em seqüência. De modo análogo, as estruturas hipertextuais de catalogação, arquivamento e recuperação da informação criam, provavelmente, novas estruturas mentais e maneiras de construir e pensar sobre o conhecimento. A hipótese é a de que as formas hipertextuais podem representar um aumento da própria capacidade intelectual humana.

\section{Full-text e os problemas do texto eletrônico}

Localizar as informações bibliográficas na Internet através de catálogos é uma etapa relativamente rápida. Acessar o documento, entretanto, quando possível, pode demorar até várias semanas. A automação dos catálogos é, portanto, um primeiro passo que deve ser seguido, evolutivamente, pelo acesso remoto do texto completo da obra ${ }^{20}$. Esta idéia, naturalmente, enfrenta ainda vários obstáculos, como será visto mais adiante.

O Projeto Gutenberger, por exemplo, talvez seja a mais conhecida das diversas iniciativas de disponibilizar na Internet (através de trabalho voluntário e de doações) os textos completos de livros cujos direitos autorais encontramse vencidos. Tal projeto pretende, até 31 de dezembro de 2001, colocar gratuitamente à disposição dos usuários da rede milhares de textos eletrônicos. Estes documentos são disponibilizados em ASCII, uma vez que, conforme observa Michael Hart, o organizador do projeto, sistemas operacionais e programas se obsoletizam, mas plain vanilla text não. 


\section{Outras coleções}

As possibilidades que a mídia digital abre para outras coleções são bem exemplificadas pelo WebMuseum ${ }^{22}$. Criado em 1994, por Nicolas Pioch, este endereço tornou-se conhecido como o "Louvre Virtual". Uma das maiores vantagens de tal iniciativa foi que disponibilizava não só algumas das obras mais conhecidas entre as tradicionalmente encontradas naquele museu, mas também cópias de muitas outras afins (mesmo autores e/ ou escolas artísticas) que pertenciam a coleções particulares e que o visitante não poderia acessar, mesmo que se deslocasse fisicamente até o Louvre concreto. Podemos dizer que tal exposição era uma versão simultamente enriquecida e emprobrecida comparada a experiência real: empobrecida porque a resolução atual da tela, meros 72 pixels por polegada (e apenas 256 cores), é ainda muito inferior à experiência do contato com a obra original, mas, ao mesmo tempo, enriquecida porque não só disponibilizava acesso àqueles impossibilitados de se deslocarem até Paris, como também por disponilibizar estas outras obras, que tal deslocamento não permitiria ver, todas as quais o usuário poderia "copiar" para seus micros locais para dar-lhes o destino que quisesse.

Outro exemplo interessante, o projeto National Digital Library Program ${ }^{23}$, da Library of Congress para a Internet (e beta-testado em CD-ROMs), foi recentemente disponibilizado on-line e abrange a reprodução de documentos não textuais, entre os quais o da Biblioteca do Vaticano. Este último envolve a seleção de 150 mil manuscritos e 100 mil gravuras e miniaturas ${ }^{24}$ e está sendo criado em parceria com a PUCRJ.

A tecnologia evolui rapidamente nesta área e até mesmo cópias tridimensionais poderão ser acessadas em um futuro não muito remoto. O próprio Projeto Gutenberg tem previsto para o ano 2001 a disponibilização de quadros utilizando uma técnica que se baseia nos CAT e MRI scans, conhecida como Replicator TecnologyTM, que faz o scanning não apenas da superfície dos objetos, mas de suas características tridimensionais e que será tão facilmente reproduzível como uma fotocópia colorida. A Apple Computers ${ }^{\circledR}$ já disponibiliza, com o sistema operacional de seus computadores, o QuickTime VRTM, uma tecnologia que permite modelar, editar, manipular e reproduzir vídeo tridimensional.

\section{OBSTÁCULOS ATUAIS}

\section{Legais e éticos}

Apesar de a impressão analógica (em papel) ser ainda indispensável (visto que atende às necessidades de um grande público que não mudará em um futuro próximo), mais e mais editores começam a optar por publicar documentos eletrônicos. A cautela existente é justificada, acima de tudo, pela necessidade de encontrar soluções que preservem os aspectos legais e éticos envolvidos principalmente na distribuição de documentos, até que surja uma nova ótica destes problemas.

A tecnologia de produção de documentos digitais desenvolveu-se mais rápidamente do que instrumentos legais para protegê-la. As novas leis de propriedade intelectual que estão sendo discutidas nos EUA, por exemplo, procuram alcançar um equilíbrio entre a proteção ao direito autoral (a fim de garantir ao autor o lucro de seu trabalho) e o interesse público maior de assegurar/garantir o mais amplo acesso possível à informação ${ }^{25}$.

\section{Econômicos (uma economia baseada em serviços e informações)}

A Biblioteca Virtual parece ser uma resposta à redução constante das verbas para ampliar a coleção e manter as assinaturas de periódicos, mas esta também tem seu custo. $O$ equipamento necessário (e seu regular upgrade), as assinaturas e taxas de acesso a bases de dados externas, licenças e aquisição de CD-ROMs etc., manutenção, treinamento e atualização permanente do staff representam um gasto inevitável.

O mero acesso à informação on-line não significa que esta informação seja sempre gratuita. Isto quer dizer que os centros distribuidores de informação costumam ter, com frequência, um retorno de seu investimento de coleta, tratamento e disponibilização de informações, cobrando taxas de acesso e serviços. Sobre isto, naturalmente, há muita con- trovérsia. Melville Dewey, o fundador do sistema decimal de classificação bibliográfica que todos conhecemos, possuía como motto "Free as water, free as air, free as information". Tivesse ele vivido atualmente, seria provavelmente "um hacker convicto, um Robin-Hood cuja maior alegria seria entrar nos sistemas computacionais [tarifados] para libertar os oceanos de informação que beneficiassem as massas" ${ }^{26}$.

É Michael Hart (do Projeto Gutenberg) que, como um David eletrônico, acerta algumas pedradas nos Golias atuais (a Microsoft, por exemplo, que está comprando os direitos autorais de milhares de imagens de obras de arte, ou as novas leis que estendem os direitos autoriais, ou ainda as taxas de acesso para acesso às bases de dados privadas) ao disponibilizar on-line. gratuitamente, através de trabalho voluntário de dezenas de colaboradores em todo o planeta (sob os auspícios da Beneditine University em Illinois), um número crescente de textos importantes ${ }^{27}$.

\section{Ausência de padrões para descrição de páginas}

Uma das maiores queixas relativas à emergência de uma biblioteca virtual é a de que, para acessá-la, atualmente, é necessário memorizar longos e bizarros endereços, abreviaturas e siglas, enfim, todas as idiossincrasias de diferentes códigos de acesso e recuperação de dados, tanto on-line, quanto em mídias óticas ou magnéticas. Não há muitos standards (ainda que o Z39.5028 seja um bom começo) ou índices abrangentes, exceto as próprias ferramentas navegacionais genéricas, falhas e com diferentes sintaxes e os múltiplos formatos para encapsular textos (ASCII, Mime, binhex, EPS, HTML etc.) mais os diferentes formatos para imagens, áudio e vídeo.

Uma coisa é, portanto, a criação de depósitos digitais, e outra, distinta, é garantir que tais registros estarão sempre disponíveis e atualizados. Alguns lugares resolvem este problema, optando por ASCII "puro", como no Projeto Gutenberg. Outros optam pelo que é chamado de technology refreshment, onde os documentos são periodicamente atualizados (tanto em mídia quanto em formatos, versões, programas etc.). 
O Research Libraries Group Preservation Program ${ }^{29}$ da American Libraries Association $^{30}$ dispõe de Anais da Conferência de 1994, realizada na Cornell University, com depoimentos e soluções de mais de 90 instituições participantes que optaram por arquivar seus documentos desta forma.

\section{Metáforas e interfaces}

Os anos atuais são conhecidos como "clicantes". Tal adjetivo define a evolução de uma interface de comandos textuais para uma interface icônica, que é apresentada como uma coleção de objetos análogos aos do mundo real. São símbolos aos quais foram associados significados que mediam nossa interação (sensória, cognitiva e emocional) com os computadores. Estas interfaces, baseadas em metáforas familiares, visam a dar poder a bibliotecários e usuários, de modo a garantir-lhes o controle das operações a serem realizadas. $\mathrm{Na}$ construção de uma interface, equipes interdisciplinares estudam as "tarefas" a serem feitas e escolhem as "ferramentas" e esquemas conceptuais que mais metaforicamente se adeqüem à tarefa proposta. "Toda interface é uma arena humanamente construída para a realização de alguma tarefa que envolva a interação homem-computador, tal como a maçaneta é a interface entre nossa mão e a porta..."

São as metáforas escolhidas para representar o acesso aos documentos eletrônicos que determinarão as interfaces utilizadas. Por exemplo, usam-se atualmente as de "navegar" ou "surfar" no "oceano" ou no "ciberespaço" de informações contidas em formato eletrônico. E, com perturbadora freqüência, pela ausência de mapas (interfaces) adequados, os usuários ainda ainda "se afogam" ou "se perdem" neles.

Existe, neste momento, um sistema muito rudimentar de mapas e guias de viagem e assiste-se recentemente ao nascimento de indexadores automáti$\cos$, ainda muito toscos. Falta um sistema eficiente para conectar estes diferentes lugares. A metáfora para alguns é a de um veículo que os levará até o(s) documentos(s) desejado(s), ou de um "agente" inteligente personalizado. A tendência é utilizar cada vez mais aplicações de inteligência artificial e expert systems, que "aprendam" e "pensem" junto com o usuário. Tais aplicativos não apenas representam o conhecimento de forma coerente para o usuário (amenizando as diferenças entre as múltiplas interfaces e formatos de dados), mas também auxiliam-no a buscar, filtrar e avaliar documentos, orientando quanto a descritores, palavras truncadas, operadores booleanos e toda as estratégias utilizadas nesta atividade, limitando e selecionando as que forem relevantes.

\section{RAZÕES PARA MUDAR}

\section{Automação dos serviços de referência, catalogação e indexação}

Uma das vantagens mais óbvias oferecidas pelas novas tecnologias às bibliotecas é a possibilidade de automação dos serviços internos. Neste caso, a automação significa apenas que as pessoas continuarão a fazer o que sempre fizeram, só que, em vez de usar uma máquina de datilografia, cartões e um fichário metálico, estarão usando um computador e realizando as tarefas de forma mais rápida e eficiente, tornandose profissionais mais produtivos.

O catálogo remoto não é uma invenção da era digital. Desde o século XIX, catálogos impressos permitiam que os usuários examinassem as listas bibliográficas de determinadas bibliotecas. Isto acabou na virada do século, quando esses deixaram de ser impressos e foram disponibilizados em cartões. Em 1972, a DIALOG começou a disponibilizar acesso por linha discada a bases de dados, porém isto era realizado por uma bibliotecária especializada, e não pelos usuários. São os catálogos remotos como os OPACs que alteram os paradigmas tradicionais e criam a necessidade de repensar a função do bibliotecário de referência.

\section{Preservação de documentos (da informação, dos direitos intelectuais)}

Outra força que impulsiona a transição da mídia impressa para a digital é a rápida degradação dos documentos cujo suporte é o papel acidificado. Isto tem sido feito com microfichas, porém a mídia digital abre outras possibilidades mais flexíveis e eficientes.
A mudança de suporte implica tão-somente a preservação da informação e não na preservação física do documento na mídia original. O suporte digital resolve, portanto, apenas uma parte da questão e cria novos problemas: o da obsolescência das tecnologias de preservação, armazenamento e recuperação (hardware, software, sintaxe etc.) e, dada a facilidade de manipulação de dados pela mídia digital, o da autenticidade.

Este problema da preservação "intelectual" se refere à integralidade e autenticidade dos documentos que podem ser corrompidos intencional ou acidentalmente, "... uma vez que a grande vantagem da mídia digital é também sua grande fraqueza: a facilidade com que uma cópia integral pode ser criada empata com a facilidade com que este documento pode ser alterado sem deixar vestígios." ${ }^{2}$

A maleabilidade do documento eletrônico, ao mesmo tempo sua segurança e vulnerabilidade, tem preocupado todos aqueles envolvidos com questões de preservação e de autoria. Diferentes versões de um mesmo documento autênticas ou não, ou mesmo apenas o mesmo documento em diferentes estágios de acabamento, representam um pesadelo para os profissionais da informação:

A seguir, estão alguns problemas levantados sobre este assunto.

1. Como se pode ter certeza de que o documento que está sendo acessado é aquele que foi solicitado?

2. Como se pode ter certeza de que o documento encontrado é o mesmo cuja referência foi feita em uma nota de rodapé?

3. Como se pode ter certeza de que o documento atual está íntegro e não foi modificado desde a última vez em que foi acessado?

Pode-se ainda acrescentar, por exemplo, que, dada a fluidez com que a informação se transforma e sites, diretórios, arquivos são criados e desativados, como se pode ter certeza de que o documento referenciado continuará amanhã disponível naquele mesmo endereço? 
Em função destes problemas, cada vez mais, autores e usuários têm, como Levy, uma atitude bem radical sobre este tema : "Não me interesso mais pelo que pensa um autor inencontrável, peço ao texto para me fazer pensar aqui e agora"33.

\section{Imprimir \& distribuir versus distribuir \& imprimir}

A rotina dos cortes nas verbas das bibliotecas acadêmicas tem determinado que 0 acesso a novos livros e periódicos se torne progressivamente mais difícil. Os custos de produção e distribuição destes documentos têm aumentado consistentemente. Por outro lado, a produção e distribuição de documentos eletrônicos em CD-ROMs e, principalmente, na Internet oferecem inúmeras vantagens. Entre elas, o custo reduzido, a velocidade do processo, a amplitude potencial de acesso e disseminação, a inclusão de dados baseados em tempo (vídeo, áudio, animações), a facilidade de atualização e/ou inclusão de novos dados, as funções de busca e indexação dos artigos e a rede hipertextual com âncoras para outros documentos afins.

No final de 1995, já havia mais de 100 peer-reviewed periódicos e centenas de outras sem revisão por algum tipo de equipe editorial. Algumas existem paralelamente a uma versão impressa, com apenas o sumário e os abstracts disponíveis on-line. Outras em versão exclusivamente eletrônica, com estas mesmas características (os artigos fulltext podem ser obtidos por ftp ou por contato via o e-mail do autor) e, finalmente, aquelas completas, full-tex ${ }^{34}$.

As possibilidades abertas por este tipo de troca de informação tem mudado a natureza da comunicação científica, tecendo uma rede hipertextual ou "hipermidial" que só pode existir no computador.

Outra modalidade que surge nesta área é a de disponibilizar, junto aos documentos eletrônicos, espaço para reviews espontâneos enviados por leitores via e-mailou formulários em HTML, bem como criando a distinção entre os periódicos (refereed e orientados de forma mais tradicional) e os archives (sem referees), muitos dos quais diariamente atualizados.
Progressivamente, as editoras voltamse para este novo suporte, dilaceradas entre o medo de perder clientes, se disponibilizarem dados na mídia eletrônica, e o desejo de obter rendas extras, aproveitando as vantagens do novo suporte. Para tanto, arrastando da mídia impressa conceitos como o de "direito autoral", procuram coibir publicações individuais de seus autores, ameaçando não considerar como um original os documentos que já tiverem sido disponibilizados ao público via www ou ftp.

\section{Compartilhar recursos (catálogos, documentos, coleções etc.)}

À medida que o mundo se torna um conglomerado de computadores e pessoas interconectados, novos modos de trabalho colaborativo se fazem possíveis, dando origem a marcadas mudanças de comportamento e de modos de construir conhecimento. Cada vez é mais rápido e barato mover idéias e informações, em vez de pessoas. Coleções compartilhadas reduzem o trabalho relativo à manutenção das mesmas e permitem transcender os limites físicos da biblioteca e de seu orçamento.

Isto é percebido com clareza quando observamos que o custo do arquivamento eletrônico de uma obra como Alice no País das Maravilhas caiu, em uma só década, de US\$10,00 por um disquete de 8 " (160Kb) para menos de 10 cents de um disquete de 3.5 " (1.44Mb). Caso fossem utilizadas técnicas banais de compressão, este custo poderia ser reduzido para menos de 1 cent. Se tais custos forem compartilhados, uma vez que a localização física dos documentos torna-se secundária, desaparece uma parte importante das limitações econômicas para a construção de bibliotecas virtuais.

\section{Personalização dos documentos}

Seguindo a tendência de "desmassificação" da sociedade em geral e da informação em particular, os documentos eletrônicos permitem um acesso bastante personalizado e podem sofrer manipulações analógicas como mudar tamanho, tipos e cor de letra. Muitos destes documentos eletrônicos, como os Expanded Books criados pela Voyager (a primeira importante editora de livros eletrônicos nos Estados Unidos), per- mitem também que o leitor faça anotações nas "margens" das folhas (que podem ser recuperadas, pois ficam indexadas palavra por palavra), crie uma "orelha" digital ou coloque marcadores de páginas, enfim que repita ações tradicionalmente associadas com a página impressa, além de outras, próprias do hipertexto, como guardar a história da navegação de leitura sinalizando os links percorridos.

Além disto, via software e hardware especial nos computadores compatíveis com IBM, ou como capacidade integrada no próprio sistema operacional nos computadores da Apple $\AA$, o texto pode ser "lido" com diferentes vozes para aqueles com deficiências visuais, para crianças ou qualquer um que quiser "ouvir" o documento (alguns vezes inclusive com a voz do próprio autor). Muitos dos clientes do Projeto Gutenberg são pessoas cegas que, uma vez feito o download, utilizam sintetizadores de voz para "ouvir" o texto. Esta "capacidade" torna-se também uma opção desejável para pessoas que não perderam completamente a visão, porque, como está fartamente documentado, a legibilidade da tela é ainda muito inferior à da página impressa. Isto leva-nos a um momento de síntese entre a literatura oral e a impressa que é inédito e cujas conseqüências ainda estão por serem estudadas.

Entre outras obras produzidas pela Voyager, encontra-se também um CD-ROM com o texto completo de Macbeth, segundo a New Cambridge Edition, comentado, com vídeo e áudio de todas as cenas, ancorado hipertextualmente em documentos afins (mapas, gravuras etc.), mas cuja característica mais instigante é a possibilidade de escolher um personagem e, por meio de um recurso semelhante ao kareokê, recitar suas falas integradas com a triIha de áudio da peça. Em resumo, este CD-ROM torna possível a uma pessoa apenas "contracenar" virtualmente com uma companhia shakespeareana. 


\section{CONSEQÜÊNCIAS PREVISÍVEIS ATUALMENTE}

\section{Arte da tipografia sendo substituída por iconografia?}

O uso do suporte digital cria novos espaços de informação que reproduzem inicialmente o referencial anterior - o modelo da página impressa, da mesma forma como Gutenberg reproduziu ligaduras, abreviações, fontes e leiautes característicos do codex nos documentos que imprimiu.

De modo semelhante, o espaço da tela começa aos poucos a ganhar identidade e criar uma linguagem adaptada a pouca legibilidade do estado da arte atual de monitores de vídeo, substituindo textos por imagens icônicas, sempre que possível. O que era chamado de texto ganha, inclusive, outras características, onde elementos novos, como o cursor, são ferramentas para uma inédita interatividade.

\section{Dissolução da barreira bibliotecário/ editor}

Como foi dito anteriormente, na Idade Média, as bibliotecas e as editoras eram o mesmo local (o scriptorium), administrado pelas mesmas pessoas (os monges escribas) e com tradições antigas e sólidas. "Os livros eram caríssimos, difíceis de produzir e de reproduzir. Cada um deles custava o equivalente a uma pequena propriedade rural." ${ }^{35}$ Curtir peles para transformá-las em pergaminhos, acumular códices, copiá-los e guardálos eram tarefa destes monastérios, mas faltava ainda uma maneira sistemática e uniforme de organizá-los e disponibilizá-los. A maioria das bibliotecas de mosteiros possuía tão poucos volumes, que um catálogo não era necessário. Com a introdução da tecnologia dos tipos móveis e do papel, a figura do publicador dissocia-se da dos monges bibliotecários de forma definitiva.

Esta transição processou-se de modo muito lento, porque, entre outras coisas, por um longo tempo ainda os livros impressos (o primeiro exemplo de produção de série) foram considerados artigos de segunda categoria e muitos recusavam-se a possuí-los, acreditando que tal produto jamais substituiria o códex. De fato, ambos coexistiram por um certo tempo até que as vantagens do impresso prevaleceram. A proliferação dos livros e a gradual criação de um público leitor acabou por exigir a criação de sistemas indexadores e catálogos bibliográficos mais completos. Inversamente, hoje em dia, diversos bibliotecários tem retomado a tarefa de disponibilizar cópias (na Internet) de determinados documentos e, inclusive, de editá-los. As oportunidades disponibilizadas pela tecnologia, na Renascença ou atualmente, são responsáveis pela alteração dos papéis tradicionais relacionados com o armazenamento, a recuperação e a distribuição da informação. As novas maneiras de apresentála, mesmo que ainda caóticas, são um campo emergente e cheio de oportunidades para os profissionais da informação. As barreiras entre bibliotecários e publicadores começam a tornar-se, outra vez, indistintas ${ }^{36}$.

\section{Dissolução da barreira autor/editor}

Com a gradual redução da literatura oral e as oportunidades de divulgação oferecidas pela nova mídia, os autores precisaram recorrer às editoras para serem lidos e conhecidos. O que impediu por muitos séculos estes autores de autopublicarem-se eram os elevados custos envolvidos na produção e distribuição dos documentos impressos. Atualmente, entretanto, qualquer um pode fazêlo a um custo reduzido e muitos já o fazem, mesmo sob a ameaça das editoras. Existe inclusive um crescente de autores que compartilham a opinião de Harnad ${ }^{37}$, que, em uma "Proposta Subversiva", conclama os colegas a publicarem-se eletronicamente e não abrirem mão de seus direitos autorais para os editores, uma vez que estes últimos terão de curvar-se e "aceitar a nova situação ou mudar de profissão", pois sua profissão depende do fornecimento de manuscritos por parte dos autores.

Harnad baseia-se no fato de que, diferentemente dos autores comerciais, os autores acadêmicos publicam não só para disseminar o conhecimento científico, mas também para assegurar sua ascensão funcional e profissional. Disponibilizando seus artigos na Internet de forma gratuita, estes autores garantiriam o registro de sua produção, ao mesmo tempo em que "passariam por cima" dos editores, das cópias ilegais nas máquinas de fotocópias, das limitações dos orçamentos das bibliotecas e da obsoletização vertiginosa da informação impressa, fazendo sua pesquisa disponível à comunidade acadêmica e aos interessados ${ }^{38}$. E mais ainda, se necessário (dada a importância do problema da circulação de dinheiro na rede), micropagamentos com preços equivalentes a uma fotocópia, junto com a criação de um ethos acadêmico consistente, mais as técnicas de autenticação de documentos, garantiriam a criação e a disseminação de conhecimento compatível com a voracidade da Era da Informação.

\section{Dissolução de certas diferenças entre bibliotecas e livrarias}

Outra entidade que começa a transformar-se com as possibilidades oferecidas pelas mídias digitais são as livrarias. Estas também disponibilizam on-line os catálogos bibliográficos de seu acervo. Tanto elas quanto determinados bancos de dados cobram pelo o acesso fulltext. As livrarias cobram o preço da aquisição e remessa pelo correio da obra impressa, as bases de dados on-line cobram a taxa de acesso e a quantidade do download. Mais ainda, algumas livrarias, como, por exemplo, a Amazon Books ${ }^{39}$ (1,5 milhão de títulos), oferecem novas opções de serviços, como buscas mediante de diferentes tipos de indexação, possibilidade de ler um resumo ou comentário sobre cada obra, bem como possibilidade de o leitor registrar e disponibilizar on-line seu comentário voluntário. Igualmente interessante, o serviço EYES, na mesma livraria, é um knowbot que notifica o e-mail do usuário cada vez que um novo livro, cujos descritores pertençam à lista especificada por este, passa a integrar o catálogo, como se houvesse uma bibliotecária de referência particular esquadrinhando as prateleiras em busca permanente e personalizada, muito semelhante ao serviço de ALERTA, que algumas bibliotecas disponibilizam para determinados pesquisadores.

Uma reflexão inevitável é o que acontecerá quando bibliotecas e livrarias disponibilizarem o mesmo texto completo do livro on-line? Quais as diferenças que haverá entre seus serviços? Que mercado de trabalho estas novas livrarias abrem para o profissional da informação? 


\section{Novos paradigmas na ciência da informação}

Para que se tornassem populares, os livros precisaram soltar-se dos cadeados das bibliotecas medievais e tornarem-se menores, mais leves e mais baratos. Mesmo assim, por séculos, a palavra escrita, um dos fundamentos da civilização ocidental, foi acessada apenas por uma minoria muito restrita. Mesmo hoje o público leitor não engloba $100 \%$ da população mundial.

"Quando os primeiros computadores apareceram, também eram extraordinariamente caros e atendidos por uma ordem monástica de programadores e matemáticos. A idéia de que esta tecnologia se tornaria barata, portátil e popular era tão incrível quanto a de que os manuscritos com iluminuras pudessem levar aos livros de bolso, descartáveis, atuais"40.

Os tipos móveis, que tornaram a informação disponível para além dos limites do mundo medieval, produziram uma explosão de conhecimento que lançou a civilização ocidental na Idade Moderna. Como foi visto anteriormente, estas poucas décadas de tecnologia digital já estão provocando transformações aceleradas. Começa a despontar um novo ecossistema informacional em que a relação entre autores, leitores, editores (publicadores), bibliotecas e livrarias torna-se menos precisa e está em constante transformação.

\section{ALGUNS DESAFIOS}

\section{Crise de identidade: mudar ou obsolescer}

Para fins metafóricos, volta-se à comparação com as bibliotecas medievais: as coleções de livros acorrentadas às prateleiras são coisas de um passado remoto. Por muitos séculos, entretanto, a idéia de que os livros pudessem ser "emprestados", levados para serem lidos e consultados na "casa" dos usuários, por exemplo, parecia uma idéia arriscada e irresponsável. Quem garantiria que as obras não seriam danificadas? E como controlar o impacto da informação livremente distribuída? Claro que, ainda hoje, a parte mais preciosa e insubstituível de cada coleção permanece na seção de "livros raros", "arquivos" ou de "reserva". Mas o resto, assim como a lâmpada que queima e não é consertada, ou o micro-chip que se avaria e é substituído, tem sua circulação livre e irrestrita.

A função principal da biblioteca tem sido a de manter a memória coletiva da sociedade. No caso da Internet, trata-se de uma memória coletiva distribuída, volátil, em constante transformação. A natureza destas informações parece requerer também que novas maneiras de tratamento sejam desenvolvidas, de forma que a importância de conceitos como "autoria", "autenticidade", "permanência" seja repensada.

A maioria dos autores que aborda o assunto das bibliotecas virtuais, entre os quais Lancaster, concorda que é uma situação que pode ser vista como "uma ameaça ou como uma oportunidade"41. O tipo de informação disponível na Internet atualmente tem características únicas. Encontrar estas informações, desenvolver políticas para identificá-las e indexá-las, desenvolver procedimentos para compartilhá-las, repensar a validade dos critérios existentes em face das necessidades da comunidade virtual representam um dos maiores desafios aos bibliotecários na época atual.

\section{Autenticação de documentos}

Uma das soluções sendo estudadas para resolver o problema da autenticidade da informação (naqueles casos em que esta é essencial) é por meio de algoritmos embutidos no software de criação do documento. Entre estas propostas, uma das mais promissoras parece ser a chamada DTS - Digital Time Stamp (Bayer, Haber e Stornetta, 1993), que utiliza técnicas criptográficas (análogas as que se encontram usadas com freqüência cada vez maior para garantir, por exemplo, sigilo no envio do número de cartões de crédito na Internet). Semelhante a um carimbo, o DTS autentica um documento em um determinado momento. Funcionando dentro da mesma arquitetura cliente-servidor, o usuário que recupera um documento pode enviá-lo a um servidor onde está o documento original para conferência e autenticação. Outra possibilidade mais simples sendo testada é a do algoritmo que realiza a soma do número total de bits de um documento, número este que é então encriptado e incorporado ao mesmo ${ }^{42}$.

\section{O acaso e a bibliografia}

É fato conhecido que o acaso também faz parte dos fatores que influenciam a escolha da bibligrafia sobre a qual se apóia a maioria dos documentos. As funções do bibliotecário de referência especializado, entretanto, incluíam auxiliar na construção desta bibligrafia, participando ativamente da seleção de autores cuja relevância Ihes garantia presença em uma lista bibliográfica respeitável e minimizando a incidência do acaso. Na elaboração deste artigo, entretanto, a bibliografia acessada on-line foi escolhida parte por referências, citações e resumos feitos nas listas de discussão sobre biblioteconomia, mas parte aleatoriamente, partindo dos apontadores de tais referências ou simplesmente por serem os primeiros itens em listas montadas por knowbots.

Isto nos leva a deduzir que, à medida que documentos encontram-se disponibilizados on-line (em quantidades cada vez maiores) e o usuário remoto faz uso de programas indexadores e links hipertextuais para montar uma bibliografia, 0 aleatório passa a desempenhar importante função. Surgem linhas de pesquisa, como a de Brenda Dervin, que desde a década passada visa a entender "como as pessoas constroem sentido em seus mundos e, em particular, como constroem necessidades informacionais e usos para estas informações" fase (atualmente) na informação disponível no ciberespaço.

Como conseqüência mais imediata, são construídos documentos e conhecimentos que representam um recorte muito particular de determinado assunto. Confrontando a bibliografia deste artigo com as de outros autores sobre esse mesmo tema, observa-se que alguns documentos são comuns mas uma boa percentagem da bibliografia é absolutamente "pessoal", isto é, denota os delimitadores pessoais do total da bibliografia existente sobre o tema naquele dado momento em que o documento foi elaborado. As vantagens e desvantagens de tal situação ainda estão por ser definidas. Pode-se pensar que diferentes bibliografias "enriquecem" a leitura do tema, mas talvez a ausência de um vocabulário ou ótica comum também possa criar estruturas conceituais paralelas e isto interfira na construção de estruturas cognitivas comuns. 


\section{Enfrentar a anarquia atual}

Como a Internet é descentralizada, não há padrões comuns para a disponibilização de documentos. Por causa disto, sente-se, com clareza, a necessidade urgente de desenvolver grupos, políticas e métodos padronizados, não só para uma revisão, seleção e indexação permanente, consistente e útil dos documentos, como também para criar formatos comuns e "atualizáveis". Os guias impressos não conseguem manter-se atualizados, porque, dada a velocidade com que surgem e desaparecem informações na rede, tornam-se obsoletos antes mesmo de serem impressos.

Com a multiplicidade de formatos criados nestas poucas décadas de mídia digital, "... estamos revivendo, no ciberespaço, as confusões e frustrações acontecidas no Século XV"44. Acessar informação nos manuscritos das bibliotecas medievais também era difícil, não só porque implicava o deslocamento físico até onde o documento "residia", mas também porque não havia consistência ou existência de elementos que auxiliassem a sua estrutura (uma vez que cada scriptorium ou copista tinha seus próprios métodos de organizá-la) e até coisas simples, como pontuação, não haviam sido inventadas ou sistematizadas.

\section{PALAVRAS FINAIS}

Ao longo deste artigo, foi intencionalmente enfatizado da comparação entre a "transição do manuscrito para o impresso" e a do "impresso para o digital", de modo a colocar o problema em uma perspectiva diacrônica e mostrar que a tecnologia faz parte da história das bibliotecas. É importante tentar entender o contexto histórico, econômico e cultural no qual estas mudanças emergem. A automação permitiu que as bibliotecas melhorassem novamente, expandissem e agrupassem atividades e serviços mais úteis para usuários e staff, enfim, que enfrentassem os desafios competitivos atuais. O processador de texto, bancos de dados, e-mail, fax, todos estes novos recursos tecnológicos tornam-se rotina na biblioteca ${ }^{45}$. Os computadores começaram como sendo algo externo, que vinha "pronto" e que os bibliotecários apenas utilizavam. Gradualmente estes profissionais foram apropriando-se da tecnologia digital, refutando soluções externas prontas, exigindo participação na elaboração dos projetos, envolvendo-se e criando novas alternativas, tomando parte ativa na instrução quanto ao uso da tecnologia e na elaboração de documentação e guias para usuários: expandindo das funções do bibliotecário para incluir também as de editor, de educador e de avaliador. As transformações criam outra vez a necessidade ou oportunidade de estes profissionais redefinirem-se, tal como fizeram em momentos anteriores, com o surgimento do pergaminho, dos códices, da imprensa etc.

A transição do paradigma da propriedade para o paradigma do acesso implica em uma mudança institucional inevitável, mas semelhante a outras acontecidas anteriormente. A predominância do impresso começou a decair desde o momento em que as mídias de massa (rádio, cinema, televisão) apareceram, nas primeiras décadas do Século XX. Apesar disto, nenhuma destas mídias ocupou completamente o lugar do livro. É difícil pensar (pelo menos neste momento) que qualquer mídia que necessite de equipamento, interface, eletricidade etc. possa substituir inteiramente os formatos impressos. Não é ainda, portanto, o caso de "isto ou aquilo".

Uma maneira de melhor entender esta situação é refletir sobre o valor do livro. Este valor pode ser desdobrado em quatro áreas: 1) o valor como suporte da informação (eficiência, economia, flexibilidade, portabilidade etc.); 2) o valor estético (tipográfico, ilustrações, encadernação, legibilidade etc.); 3) o valor histórico (registro de determinadas informações em um determinado formato em um determinado momento); 4) o valor afetivo (o que simboliza, serve de metáfora a que, que associações desperta?). Quando se fala no livro e em seu valor como suporte de informação, não há por que não pensar em utilizar os suportes/formatos mais eficientes e modernos (a propósito, como seriam vistas, hoje em dia, as pessoas apegadas ao pergaminho como suporte?). Evidentemente, os valores estéticos, históricos e, igualmente importante, os afetivos garantem ao livro sua permanência, a despeito da evolução do formato. Assiste-se à transformação, e não à morte do livro. Indo uma etapa além do li- vro, da mesma forma como existiu uma etapa além do papiro, apenas que desta vez em ritmo mais acelerado.

O meio eletrônico também permite a criação de um espaço inigualável para promoção do livro ${ }^{46}$, onde se multiplicam grupos de discussão de bibliófilos, bibliotecários, editores, autores, colecionadores, pontos de venda on-line de editoras e livrarias, estimulando a criação de novos públicos leitores e permitindo uma interação inédita entre autores, editores, leitores e bibliotecários.

O aumento da procura por fontes eletrônicas de informação exige que sejam desenvolvidas novas estruturas para organizar esta informação contida nas novas bibliotecas, estruturas estas que estarão sempre a evoluir e a aprimorarse tanto quanto a tecnologia permitir. Daí a importância de auxiliar a descobrir o sentido, a interpretar a informação contida nos dados, em oposição a mero armazenamento e transmissão dos mesmos, e participar ativamente da construção social do conhecimento que as novas mídias oportunizam.

Faz-se necessário reconhecer que somos todos parceiros, relutantes ou entusiasmados, necessitando adquirir novas habilidades ("alfabetização" digital) para alcançar as mesmas antigas metas (informação e conhecimento) e precisando também reavaliar constantemente nossos conceitos sobre tais assuntos. A influência do impresso é ainda tão forte que a maioria das metáforas usadas para descrever o novo suporte usa terminologia e imagens advindas deste momento tecnológico anterior. Semelhante ao que aconteceu com relação à imprensa, são as novas gerações que conseguirão fazer uso prático da tecnologia de modo verdadeiramente original, resolvendo também as dificuldades legais e financeiras que ainda são arrastadas do modelo impresso. É importante criar áreas novas de estudo, interdisciplinares, onde competência computacional se some à reflexão sobre estas transformações. Onde estas grandes mudanças de paradigma sejam abordadas, entre as quais a criação de novas formas de organização e trabalho, colaborativas; e a crescente necessidade de mudar a ênfase do trabalho para aqueles ligados às necessidades do usuário remoto ${ }^{48}$. 
Estima-se que apenas 1\% da informação arquivada no mundo encontre-se em formatos digitais $\mathrm{s}^{48}$. $\mathrm{O}$ restante representa um tremendo desafio em termos de desenvolvimento de ferramentas, políticas de acesso, habilidades profissionais, enfim de novas estruturas teóricas e práticas para criar uma verdadeira biblioteca universal. O mundo precisa dos bibliotecários para realizar isto.

\section{REFERÊNCIAS BIBLIOGRÁFICAS}

1. BAUENS, M. The Cybrarians Manifesto: Towards a New Organizational Model for Corporate Libraries. [on-line] Disponível na Internet na URL http://worf.ubalt.edu/ jwalz/cybrarian.html . 1993.

2. BROWNING, J. Libraries Without Walls for Books Without Pages. WIRED, San Francisco, v. 1, n. 1, 1993. p.62-65.

3. Dyson, E. et al. Cyberespace and the American Dream: a Magna Carta for the Knowledge Age. [on-line] Disponível na Internet na URL http://alberti.mit.edu/arch/ 4.207/texts/cyberspace-dream.html . 1994.

4. PEREIRA, M. Bibliotecas Virtuais: realidade, possibilidade ou alvo de sonho. Ci. Inf., Brasília, v. 24, n. 1, jan./abril, 1995. p.101-109.

5. Projeto Xanadu [on-line] Disponível na Internet na URL http://xanadu.net/ the.project

6. ROOKS, D. The Virtual Library: Pitfalls, Promises and Potential. The PublicAccess Computer System Review, v. 4, n. 5, 1993. [on-line] Disponível da Internet via correio eletrônico enviando msg para listserv@uhupvm.uh.edu: get rooks prv4n5 $\mathrm{f}=$ mail.

7. LANCASTER, F. Ameaça ou Oportunidade?: o Futuro dos Serviços de Biblioteca à Luz das Inovações Tecnológicas. Revista da Escola de Biblioteconomia UFMG, Belo Horizonte, v. 23, n. 1, jan./junho, 1994. p.7

8. LEVY, P. Toward Superlanguage. [on-line] Disponível na Internet na URL http:// www.uiah.fi/bookshop/isea_proc/ nextgen/01.html . 1996.

9. VIRILIO, P. Speed Information: Cyberespace Alarm! [on-line] Disponível na Internet na URL http://www.ctheory.com/a30cyberspace_alarm.html. Arquivo capturado em 1996.

10. LEVY, P. O que é o Virtual? São Paulo: Ed. 34, 1996. p.124.

11. HARNAD, S. Scholarly Journals at the Crossroads: a Subversive Proposal for Eletronic Publishing. [on-line] Disponível na Internet na URL http://cogsci.ecs.soton. ac.uk/ harnad/subvert.html. Arquivo capturado em 1996.

12. FIGUEIREDO, N. As Novas Tecnologias: Previsões e Realidade. Ci. Inf., Brasília, v. 24, n. 1, jan./abril, 1995. p.110-118.

13. LaRUE, J. The Library Tomorrow: a Virtual Certainty. Meckjournal. v. 3, n. 2, Feb./ Mar. 1993. [on-line] Disponível na Internet via gopher na URL gopher://gopher. cic.met:2000/11/2-serials/archive/ alphabet/metjournal. 1996.

14. Negroponte, N. A Vida Digital. São Paulo: Companhia das Letras, 1995.
15. LANCASTER, F. op. cit. p.10

16. WIELHORSKI, K. Teaching Remote Users How to Use Electronic Information Resources. [on-line] The Public-Access Computer System Review, v. 5, n. 4, 1994: 5-20. Disponível da Internet via correio eletrônico enviando msg para listserv@ uhupvm.uh.edu: get wielhors prv5n4 $\mathrm{f}=$ mail.

17. (idem)

18. OHIO COLLEGES LIBRARY CENTER. [Homepage] [on-line] Disponível na Internet na URL http://www.oclc.org. 1997.

19. LEVY, P. Toward Superlanguage. [on-line] Disponível na Internet na URL http:// www.uiah.fi/bookshop/isea proc/ nextgen/01.html . 1996.

20. LANCASTER, F. Ameaça ou Oportunidade?: O Futuro dos Serviços de Bibliotecários a Luz das Inovações Tecnólogicas. Revista da Escola de Biblioteconomia da UFMG, Belo Horizonte, v. 23, N. 1, jan/junho, 1994.

21. PROJETO GUTENBERG [HOMEPAGE] [on-line] Disponível na Internet na URL http://www.promo.net/pg/

22. $\mathrm{PIOCH}, \mathrm{N}$. WebMusean [on-line] Disponível na Internet na URL http://mistral.enst.fr/ $\sim$ pioch/louvre/ Acessado em janeiro de 1997.

23. National Digital Library Program [Homepage] [on-line] Disponível na Internet na URL http://rs6.loc.gov/ammem/ndlpedu/.

24. Doorn, P. The Electronic Labyrinth: Opportunities and Pitfalls of the Internet for Historians. Historical Informatics: an Essential Tool for Historians? A Panel Convened by the Association for History and Computing - XIX Annual Meeting. Atlanta, 1994. p.59.

25. A.L.A. Washington Office: Intellectual Property Issues. [on-line] Disponível na Internet na URL http://www.ala.org/ washoff/cd2095.html.

26. Ibidem, p.60.

27. HAMILTON, D. Hart of The Gutenberg Galaxy. WIRED, San Francisco, v. 5, n. 2, 1997. p.108-118

28. Z39.50 [Homepage] [on-line] Disponível na Internet na URL http://info.lib.uh.edu/pr/v1/ n2/hinnebus.1n2.

Exemplos de citação de fontes eletrônicas propostos pela Library of Congress [on-line] Disponível na Internet na URLhttp://rs6.loc.gov/ammem/ndlpedu/ cite.html

29. Research Libraries Group Preservation Program [Homepage] [on-line] Disponível na Internet na URL http://wwwrlg.stanford.edu/pr/pressrel.html 
30. ALA - American Library Association [Homepage] [on-line] Disponível na Internet na URL http://www.ala.org

31. LAUREL, B. The Art of Human-Computer Interface Design. Reading: Addison Wesley, 1990.

32. GRAHAN, P. Intellectual Preservation: Eletronic Preservation of the Third Kind. [on-line] Disponível na Internet na URL http:// aultnis.rutgers.edu/texts/ cpaintpress.html. Arquivo capturado em março de 1994

33. LEVY, P. O que é o Virtual? São Paulo: Ed. 34, 1996. p.49.

34. Taubes, G. Science Journals Go Wired. Science, v. 271, Feb., 1996. p.764-766

35. HART, M. Libraries Unchained: the End of Libraries. [on-line] Disponível na Internet via correio eletrônico: GUTENBERG@ UIUCVMD.BITNET. 1992.

36. FIGUEIREDO, N. op. cit. p.112.

37. HARNAD, P. Scholarly Journals at the Crossroads: a Subversive Proposal for Electronic Publishing [on-line] Disponível na Internet via FTP na URL ftp:// cogsci.ecs.soton.ac.uk/pub/harnad/ Psycoloquy/Subversive.Proposal. 1996.

\section{Virtual libraries: (r)evolution?}

\section{Abstract}

New information technologies are creating "libraries without walls for books without pages". Better known as "Virtual Libraries", these new formats and medias are redefining the existing paradigms abourt what information and communication are, as well as the scope and definition of information sciences professionals' work.

Interactivity and interdisciplinarity are the keywords. As we move into what is also caled the IInformation Era", this transition creates the need to rethink those ethical, esthetic, legal, cultural, etc. models established by the printend media. Simultaneously happening off and on-line, the "Information Revolution", another name used to describe these events, requires a wide range of hardware and software applications in order to become operative. Collection versus access, local user versus remote user, hierarchical or hypertextual indexing, print and distribute or distribute and print, surf the information ocean or drown? This article aims to discuss these issues under na interdisciplinary and a discronical perspective, contributing, perhaps, to the debate and the brainstorm created by digital media convergence.

\section{Keywords}

Virtual libraries; On-line information; New technologies.
38. Charness, Neil. To Publish or not to Publish, in the Internet. [on-line] Disponível na Internet na URL http://www.iog. wayne.edu/apadiv20/charness.htm. 1996.

39. AMAZON BOOKS - http://www.amazon. com.

40. HART, M. Libraries Unchained: the End of Libraries. [on-line] Disponível na Internet via correio eletrônico: GUTENBERG@ UIUCVMD.BITNET. 1992.

41. LANCASTER, F. op. cit. p.7.

42. GRAHAM, P. Intellectual Preservation of the Third Kind. [on-line] Disponível na Internet na URL http://aultnis.rutgers.edu/texts/ cpaintpress.html. Arquivo capturado em março de 1994.

43. DERVIN, B. An Overview of Sense-Making Research: Concepts, Methods, and Results to Date [on-line] Disponível na Internet na URL http://edfu.lis.uiuc.edu/ allerton/96/w1/Dervin83a.html . 1983.

44. ARnetT, N. Mendicant Sysops in Cyberspace. [on-line] Disponível na Internet na URL http:// www.mccmedia. com/public/medicants.html. Arquivo capturado em janeiro de 1997.

45. McCOMBS, G. (editor). How Did We Get Here: Thoughts on the Convergence of Reference and Technical Services. Access Services: The Convergence of Reference and Technical Services. Birminghamton, The Haworth Press, Inc., 1991. p.27-36.

46. Williams, S. [on-line] Disponível na Internet na URL gopher://gopher.fis.utoronto.ca/ 00/courses/2108/assig2/williams.assig2). 1994.

47. TIFFT, J<jtifft@aed.org> [on-line] cristal-ed v. 3, n. 6 , msg publicada na lista cristal-ed@sils.umich.edu (id 199503040518.AAA22266@sils.umich.edu). March 04, 1995.

48. O'REILLY \& Asssociates. The Harvard Conference on the Internet \& Society. Cambridge: Harvard University Press, 1997. p.150.

\section{Marília Levacov}

Doutora em tecnologia e mídia, Boston University.

Professora na graduação e mestrado da Faculdade de Biblioteconomia e Comunicação da UFRGS.

mlevacov@ilea.ufrgs.br 